\title{
Iron and Folate Contents of Tajik Legumes
}

\author{
Shakhlo Negmatjanovna Yarbaeva, David Giraud, Julie Ann Albrecht
}

Department of Nutrition and Health Sciences, University of Nebraska-Lincoln, Lincoln, USA.

Email: jalbrecht1@unl.edu

Received February $15^{\text {th }}, 2011$; revised March $12^{\text {th }}, 2011$; accepted March $14^{\text {th }}, 2011$.

\begin{abstract}
Seven varieties of Tajik legumes and two Tajik snack type ready-to-eat (RTE) whole/split chickpeas were analyzed for iron in raw and cooked legumes and for naturally occurring folate content in cooked legumes. Iron was measured according to AACC method 40 - 41B. Folate contents were determined by microbiological (Lactobacillus casei subsp. Rhamnosus ATCC 7469) and high-performance liquid chromatography analysis utilizing a tri-enzyme treatment (protease, a-amylase and conjugase). Folate derivatives of tetrahydrofolate, 5-formyl-tetrahydrofolate and 5-methyl-tetrahydrofolate were identified and quantified. Iron content for Tajik legumes ranged from 5.52 to $13.27 \mathrm{mg} / 100 \mathrm{~g}$ for raw; 2.81 to $4.12 \mathrm{mg} / 100 \mathrm{~g}$ for cooked and 4.37 and $4.76 \mathrm{mg} / 100 \mathrm{~g}$ for RTE chickpeas. The total folate content of cooked legumes ranged from 53 to $81 \mu \mathrm{g} / 100 \mathrm{~g}$ for beans; 133 to $203 \mu \mathrm{g} / 100 \mathrm{~g}$ for peas, and from 39 to $22 \mu \mathrm{g} / 100 \mathrm{~g}$ for small and large lentils, respectively. The predominant form of folate in legumes was tetrahydrofolate, followed by 5-formyl-tetrahydrofolate and 5-methyl-tetrahydrofolate.
\end{abstract}

Keywords: Legumes, Ready-to-Eat (RTE) Snack Type Chickpeas, Microbiological Assay, HPLC, Iron, Folate, Tajikistan

\section{Introduction}

Vitamin and mineral deficiencies (also known as "hidden hunger") are particularly prevalent in Central Asia with a high prevalence of iron and folate deficiency [1]. Anemia is the most common blood disorder in adults [2]. Both iron and folate deficiencies contribute to the prevalence of anemia [3]. The annual estimate of iron-deficiency anemia is $42 \%$ among Tajik women between 15 - 49 years old; approximately 100 maternal deaths per year occur from severe anemia [4]. In the geographic region surrounding Dushanbe (the capital of Tajikistan), but not including the capital, a high rate $(73.7 \%)$ of folic acid deficiency in women was found [5]. In Tajikistan, over 300 children annually are born with neutral tube defects [4]. Iron intake from animal products was negligible among Tajik women [5]. Folate intake from consumption of green leafy vegetables was $15.6 \% ; 11.6 \%$ from melons and pumpkins; and 1.5\% from fruits and berries [5].

A food-based approach to reduce micronutrient malnutrition in Tajikistan encourages dietary diversification through the production and consumption of micronutrient-rich foods, including appropriate traditional foods [6]. This strategy is cost-effective, sustainable and income generating; culturally acceptable and feasible to implement; and builds alliances among government, consumer groups, the food industry and other relevant organizations to achieve the shared goal of preventing micronutrient malnutrition [7].

Legumes are grown for direct human consumption, available all year, and important sources of dietary proteins, dietary fiber, iron, folate, zinc, and calcium $[8,9]$. Legumes can be milled into flour to make bread and bread products and extruded snacks [10]. In Tajikistan, chickpeas are minimally processed into a snack food which is consumed like peanuts in the US. Legumes are an inexpensive source of nutrients and are culturally acceptable both in the diet and as a crop in Tajikistan [11]. The joint FAO/WHO expert consultation on nutrition and mineral requirements states that pulses (legumes), vegetables, including green leafy vegetables and fruits are the preferred way of ensuring optimal nutrition, including micronutrient adequacy [12].

Nutritional assessment by diet analysis of a population includes the evaluation of food consumed and then converting these food items into their nutrients [13]. This process requires a food composition database which lists the nutritional values for a given food portion for foods commonly eaten by the population [13].

Therefore, the objectives of our study were to 1) evaluate the iron content of raw and cooked Tajik legumes by the orthophenanthroline spectrophotometry; and 
2) determine the naturally occurring folate contents of cooked Tajik legumes and ready-to-eat snack type chickpeas by microbiological and high-performance liquid chromatography (HPLC) methods.

\section{Materials and Methods}

\subsection{Samples}

Legumes (1000 g of each composited variety) obtained from local markets in Tajikistan were: red kidney beans (Phaseolus vulgaris); cranberry beans (Romano); blackeye peas (Vigna unguiculata), kabuli type chickpeas ( $\mathrm{Ci}$ cer arietinum); desi type chickpeas (Cicer arietinum); lentils, large (Lens culinaris); lentils, small (Lens culinaris); and ready-to-eat (RTE) whole or split kabuli type chickpeas (Cicer arietinum) (Table 1). Legumes were shipped to the US and samples were kept at room temperature until analyzed.

\subsection{Cooking Treatments}

Fifty g of legumes were soaked in $150 \mathrm{ml}$ distilled water at $4^{\circ} \mathrm{C}$ for $16 \mathrm{~h}$. The soaked legumes were held at $4{ }^{\circ} \mathrm{C}$ to minimize microbial growth. After $16 \mathrm{~h}$, the soaking water was discarded, $250 \mathrm{ml}$ distilled water was added to the soaked legumes and legumes were then cooked until doneness on an electric hot plate. Doneness was determined visually and subjectively by pressing between the fingers (approximate cooking times for beans, peas and lentils were 30, 20 and $10 \mathrm{~min}$ ). Cooked legumes were drained before analysis and stored at $-80^{\circ} \mathrm{C}$ for iron and folate determination. Weights of legumes before and after cooking were recorded. Each variety of raw and cooked legumes was analyzed in triplicate for iron measurements; for folate measurements, cooked legumes were analyzed in triplicate.

\subsection{Iron Measurements}

The AACC method 40 - 41B [14] was used for the determination of the iron content. Iron reference solution and 1, 10-phenanthroline monohydrate $\left(\mathrm{Cl}_{12} \mathrm{H}_{8} \mathrm{~N}_{2} \cdot \mathrm{H}_{2} \mathrm{O}\right)$ were obtained from Fisher Scientific (Fair Lawn, NJ, USA) and hydroxylamine hydrochloride $\left(\mathrm{NH}_{2} \mathrm{OH} \cdot \mathrm{HCl}\right)$ from ACROS Organics (Geel, Belgium). Legumes were homogenized in an Osterizer ${ }^{\mathrm{TM}}$ blender. A $5 \mathrm{~g}$ sample of raw or cooked legumes were dry ashed and dissolved in $5 \mathrm{ml}$ of concentrated $\mathrm{HCl}$ and diluted to $100 \mathrm{ml}$. A $10 \mathrm{ml}$ of the aliquot was taken for reaction with $1 \mathrm{ml}$ of $\mathrm{NH}_{2} \mathrm{OH} \cdot \mathrm{HCl}$ solution and $1 \mathrm{ml}$ of orthophenanthroline. The absorbance of each solution was measured spectrophotometrically (Beckman DU-640, Fullerton, CA) at $510 \mathrm{~nm}$ and converted to iron concentration $(\mathrm{mg} / \mathrm{ml})$ using a calibration curve.

\section{True Retention}

True retention of iron content was calculated as described by Murphy et al. [15] using the following formula: True retention $(\%)=[($ nutrient content $(\mathrm{g} / 100 \mathrm{~g})$ of cooked legume $\times \mathrm{g}$ of cooked legume)/(nutrient content $(\mathrm{g} / 100 \mathrm{~g})$ of raw legume $\times \mathrm{g}$ of raw legume $) \times 100]$.

\subsection{Folate Measurements}

\subsubsection{Microbiological Analysis}

Microbiological analysis of the total folate contents was based on Rader et al. [16] with a modification to the amount of the conjugase source. All procedures were carried out under subdued light conditions. A 25 g sample of cooked legumes was homogenized in $100 \mathrm{ml}$ of $0.1 \mathrm{M}$ phosphate buffer ( $\mathrm{pH}$ 7.0) and centrifuged for $30 \mathrm{~min}$. A $1 \mathrm{ml}\left(2 \mathrm{mg} \cdot \mathrm{ml}^{-1}\right)$ of protease (Streptomyces griseus; Sigma Chemical Co., St. Louis, MO) was added to $25 \mathrm{ml}$ extract and incubated for $3 \mathrm{~h}$ at $37^{\circ} \mathrm{C}$. Samples were heated to $100^{\circ} \mathrm{C}$, cooled and brought to $\mathrm{pH} 7.8$ with buffer. A $1 \mathrm{ml}\left(20 \mathrm{mg} \cdot \mathrm{ml}^{-1}\right)$ of $\alpha$-amylase (Aspergillus oryzae; Sigma Chemical Co., St. Louis, MO) was added to each extraction sample and incubated for $2 \mathrm{~h}$ at $37^{\circ} \mathrm{C}$. A $4 \mathrm{ml}\left(3 \mathrm{mg} \cdot \mathrm{ml}^{-1}\right)$ aliquot of chicken conjugase (Difco Laboratories, Detroit, MI) was added to each extraction sample and incubated for $16 \mathrm{~h}$ at $37^{\circ} \mathrm{C}$. Deconjugated

Table 1. Description of legumes grown and purchased in Tajikistan.

\begin{tabular}{cl}
\hline Legumes & Description \\
\hline Red, kidney beans (Phaseolus vulgaris) & - large, kidney-shaped bean; deep reddish-brown; robust, full-bodied flavor \\
Cranberry beans (Romano) & - large ovals; creamy background with burgundy highlights, pink-colored \\
Blackeye peas (Vigna unguiculata) & - kidney shaped white bean with black eye \\
Kabuli type chickpeas (Cicer arietinum) & -round, beige color; nut-like flavor ad firm texture \\
Desi type chickpeas (Cicer arietinum) & -angular, pigmented seeds, beige color; nut like flavor and firm texture \\
Lentil, large (Lens culinaris) & - seeds are round, about $1 / 2$ cm in diameter and light green in color \\
Lentil, small (Lens culinaris) & - seeds are round, brown in color mixed with dark brown seeds speckled with black \\
Chickpeas whole (RTE) (Cicer arietinum) & - round, medium size, about $1 / 2$ cm in diameter and light green in color \\
Chickpeas split (RTE) (Cicer arietinum) & - round, split, yellow color; nut-like flavor and firm texture \\
\hline
\end{tabular}


extracts were heated to $100^{\circ} \mathrm{C}$ and centrifuged. The extracted samples were appropriately diluted and used in the microbiological analysis with Lactobacillus casei subsp. Rhamnosus (ATCC No. 7469) for total folate. A folic acid $\left(200 \mu \mathrm{g} \cdot \mathrm{ml}^{-1}\right)$ standard solution was prepared according to AOAC 45.2.03 [17]. L. casei subsp. Rhamnosus was incubated for $17 \mathrm{~h}$ at $37^{\circ} \mathrm{C}$. Turbidimetric readings were carried out by using a spectrophotometer (Beckman DUß 640, Fullerton, CA) at $660 \mathrm{~nm}$. Each variety of cooked legumes was analyzed in triplicate. The growth response of the L. casei subsp. Rhamnosus (measure as turbidity at $660 \mathrm{~nm}$ ) of the total folate in the sample was compared quantitatively to standard solutions of folic acid.

\subsubsection{HPLC Analysis}

Folate derivatives of tetrahydrofolate (THF), 5-formyltetrahydrofolate (5-CHO-THF) and 5-methyl tetrahydrofolate $\left(5-\mathrm{CH}_{3}-\mathrm{THF}\right)$ in cooked legumes were identified and quantified by reversed-phase ion-pair HPLC with fluorometric detection after ion exchange solid phase extraction. Individual folate standards THF, 5-CHO-THF, 5- $\mathrm{CH}_{3}-\mathrm{THF}$, folic acid were purchased from Sigma Chemical Co. (St. Louis, MO).

\subsubsection{Sample Extraction and Purification}

After protease treatment (as described above), the $\mathrm{pH}$ was adjusted to 6.8. Rat plasma (Difco Laboratories, Detroit, MI) at a concentration of $0.5 \mathrm{ml}$ was used in $10 \mathrm{ml}$ of extract as a conjugase source. The extracts were purified by solid phase extraction (SPE) on a strong anion exchange (SAX) cartridges [Quaterny amine $\left(\mathrm{N}^{+}\right)$, Baker 7091-3] as described by Osseyi [18]. The cartridges (3-ml SPE column, $500 \mathrm{mg}$ ) were conditioned with $3 \mathrm{ml}$ of hexane, followed by $3 \mathrm{ml}$ of methanol, and then equilibrated with $5 \mathrm{ml}$ of $0.1 \mathrm{M} \mathrm{K}_{2} \mathrm{HPO}_{4}$ buffer ( $\mathrm{pH} 7$ - 8) containing $0.1 \%(\mathrm{w} / \mathrm{v})$ ascorbic acid. A portion $(4 \mathrm{ml})$ of the extract was diluted with $2 \mathrm{ml}$ phosphate buffer before loading into a column, with an elution rate of about $0.6 \mathrm{ml} / \mathrm{min}$; the volume of the portion and the extent of dilution might vary depending on the expected value of folic acid. The column was rinsed with $2 \mathrm{ml}$ diluted (1/5) phosphate buffer. Analytes were eluted with at least $4 \mathrm{ml}$ of $0.1 \mathrm{M}$ sodium acetate $(\mathrm{pH} 4.5)$ containing $5 \%(\mathrm{w} / \mathrm{v})$ $\mathrm{Na}_{2} \mathrm{HPO}_{4}$ (HPLC grade) and $0.1 \%(\mathrm{w} / \mathrm{v})$ ascorbic acid. The eluent was injected in $20 \mu \mathrm{L}$ volumes.

\subsubsection{Chromatography}

The HPLC separation was performed on Microsorb - MV $\mathrm{C}_{18}$ analytical column $(100 \mathrm{~mm} \times 4.6 \mathrm{~mm}$ I.D., $3 \mu \mathrm{m}$ particle diameter, Varian Chromatographic Systems, Walnut Creek, CA). A Brownlee $(30 \mathrm{~mm} \times 2.1 \mathrm{~mm}$ I.D. $)$ guard column with $5 \mu \mathrm{m}$ ODS packing (Varian Chromatographic Systems, Walnut Creek, CA) which was placed before a $\mathrm{C}_{18}$ analytical column (Varian Chromatographic Systems, Walnut Creek, CA). The HPLC analysis was performed using a Hitachi L-4000 UV detector operating at $280 \mathrm{~nm}$ and Waters 474 scanning fluorescence detector (Waters Corp., Milford, MA) set at an excitation wavelength of $290 \mathrm{~nm}$ and emission wavelength of $360 \mathrm{~nm}$. Chromatograms were recorded and peak areas and heights quantified using a Hitachi model D-2500 chromato-integrator. The mobile phase was composed of $26 \%$ methanol $(\mathrm{v} / \mathrm{v})$ in potassium phosphate buffer $(3.5 \mathrm{mM}$ $\mathrm{KH}_{2} \mathrm{HPO}_{4}$ and $\mathrm{K}_{2} \mathrm{HPO}_{4}$ ), $\mathrm{pH} 6.8$, containing $5 \mathrm{mM}$ tetrabutylammonium dihydrogen phosphate (Sigma Che- mical Co., St. Louis, MO) as an ion-paring agent. Ana- lyses of cooked legumes were conducted in triplicate. Recovery of folates was determined by adding a known amount of each folate form (tetrahydrofolate, 5-formyltetrahydrofolate and 5-methyl tetrahydrofolate) into the samples. The concentrations of folate derivatives in the sample were measured by comparing peak area to a standard solution.

\subsubsection{Quality Control}

Cooked legume samples were spiked with a known amount of folic acid and analyzed by microbiological and HPLC methodologies. Recovery was calculated using the following formula: \% Recovery $=[$ (ng folic acid in spiked sample - ng folic acid in unspiked sample)/ng folic acid added in spiked sample. Recovery of added folic acid averaged $93 \%-102 \%$.

\subsection{Statistical Analysis}

For all analysis, the means of three values and standard errors were calculated using statistical analysis software (SAS Institute, Inc., Cary, NC, 2000; Release 8.01). A level of $5 \%$ was considered to be significant.

\section{Results and Discussion}

\subsection{Iron Content}

Seven varieties of Tajik legumes and two Tajik snack type ready-to-eat (RTE) whole/split chickpeas were analyzed for iron content (Table 1). The effect of cooking on the true retention for iron in legumes is presented in Table 2. For true retentions of less than $100 \%$, the iron may have been lost in the soaking or cooking water. Murphy et al. [15] also reported iron retention greater than $100 \%$ in legumes and attributed this increase in foods where moisture is gained during soaking/cooking and the potential of solids are lost during cooking. In our study, the cooking water was not analyzed for iron content.

Results of analyzed iron contents of Tajik legumes were compared with the USDA Nutrient Database [19]. Tajik legumes were 35\% lower for raw and 56\% higher 
for cooked legumes than the USDA Nutrient Database [19] (Table 2). These differences may be due to varietal differences, growing conditions, storage conditions and preparation methods. Also, the soaking and cooking process that we used may have affected the higher retentions of iron in the Tajik varieties.

In our study, legumes were soaked overnight for $16 \mathrm{~h}$. Soaking legumes for some period of time is one of the common practices of Tajik households. Soaking improves iron absorption, which degrades the phytate [20]. However, according to Brazaca and Da Silva [21], the effects of tannins and phytic acid were not determining factors in diminishing the amount of dialyzed iron; rather the effect of dietary enhancers (meat and orange juice) increased the amount of iron absorption. Therefore, in addition to soaking, including foods rich in vitamin $\mathrm{C}$ (tomatoes, leafy green vegetables, bell peppers, lemon, and green onions) and/or small amount of meat to a cooked legume item may help maximize iron absorption.

\subsection{Folate Contents}

The same varieties of cooked legumes were analyzed for the folate contents by microbiological analysis and HPLC. In general, the microbiological analysis is based on quantifying the growth response of a specific microorganism, L. casei subsp. Rhamnosus, to the total mixture of folate that are present $[22,23]$. The use of the HPLC analysis allows the identification of the boilogically active forms of folate; tetrahydrofolate (THF), 5-methyl tetrahydrofolate $\left(5-\mathrm{CH}_{3}-\mathrm{THF}\right)$, and 5-formyl tetrahydrofolate (5-CHO-THF).

Legumes are rich in protein and starch; therefore, the complete extraction of folates from the cellular matrix of legume seed is essential. In our study, the tri-enzyme treatment was used, including protease, $\alpha$-amylase and conjugase [16]. Chicken pancrease was used as a conjugase source for microbiological analysis and rat plasma for HPLC. The total folate contents by microbiological analysis of cooked legumes ranged from 53 to $81 \mu \mathrm{g} / 100 \mathrm{~g}$ for beans; 133 to $203 \mu \mathrm{g} / 100 \mathrm{~g}$ for peas, and from 22 to $39 \mu \mathrm{g} / 100 \mathrm{~g}$ for lentils (Table 3). RTE whole or split chickpeas prepared and used as a snack food in Tajikistan had a high folate content ( 269 and $233 \mu \mathrm{g} / 100 \mathrm{~g}$ ) on a dry basis, respectively (Table 3 ). Our results were simi-

Table 2. Iron contents of raw and cooked legumes (Mean \pm SE).

\begin{tabular}{|c|c|c|c|c|c|}
\hline \multirow[t]{2}{*}{ Legumes } & \multicolumn{2}{|c|}{$\begin{array}{c}\text { Iron content (mg/100g dry matter) } \\
\text { of raw legumes }\end{array}$} & \multicolumn{2}{|c|}{$\begin{array}{l}\text { Iron content (mg/100g wet } \\
\text { matter) of cooked legumes }\end{array}$} & \multirow{2}{*}{$\begin{array}{c}\text { TR (\%) } \\
\text { Tajik Data }\end{array}$} \\
\hline & Tajik Data & USDA Data & Tajik Data & USDA Data & \\
\hline Red, kidney beans (Phaseolus vulgaris) & $6.98 \pm 0.51$ & $6.69 \pm 0.24$ & $3.34 \pm 0.03$ & $2.94 \pm 0.18$ & 92.01 \\
\hline Cranberry beans (Romano) & $6.31 \pm 0.05$ & $5.00 \pm 0.19$ & $3.17 \pm 0.01$ & $2.09 \pm 0.12$ & 96.19 \\
\hline Blackeye peas (Vigna unguiculata) & $5.52 \pm 0.10$ & $8.27 \pm 0.25$ & $2.81 \pm 0.11$ & $2.51 \pm 0.10$ & 111.00 \\
\hline Kabuli type chickpeas (Cicer arietinum) & $6.17 \pm 0.06$ & $6.24 \pm 0.14$ & $3.14 \pm 0.43$ & $2.89 \pm 0.15$ & 99.75 \\
\hline Desi type chickpeas (Cicer arietinum) & $6.50 \pm 0.01$ & NA & $3.27 \pm 0.18$ & NA & 101.57 \\
\hline Lentil, small (Lens culinaris) & $13.27 \pm 0.19$ & NA & $4.08 \pm 0.43$ & NA & 60.17 \\
\hline Lentil, large (Lens culinaris) & $8.45 \pm 0.43$ & $9.02 \pm 0.37$ & $4.12 \pm 0.48$ & $3.33 \pm 0.24$ & 100.19 \\
\hline Chickpeas whole (RTE) (Cicer arietinum) & $*$ & $*$ & $4.37 \pm 0.02^{2}$ & NA & NA \\
\hline Chickpeas split (RTE) (Cicer arietinum) & $*$ & * & $4.76 \pm 0.14^{2}$ & NA & NA \\
\hline
\end{tabular}

${ }^{1}$ True Retention, reference Murphy et al. (1975); NA = Not available; ${ }^{*}$ Analyzed in processed form only.

Table 3. Folate vitamers of cooked legumes (Mean \pm SE).

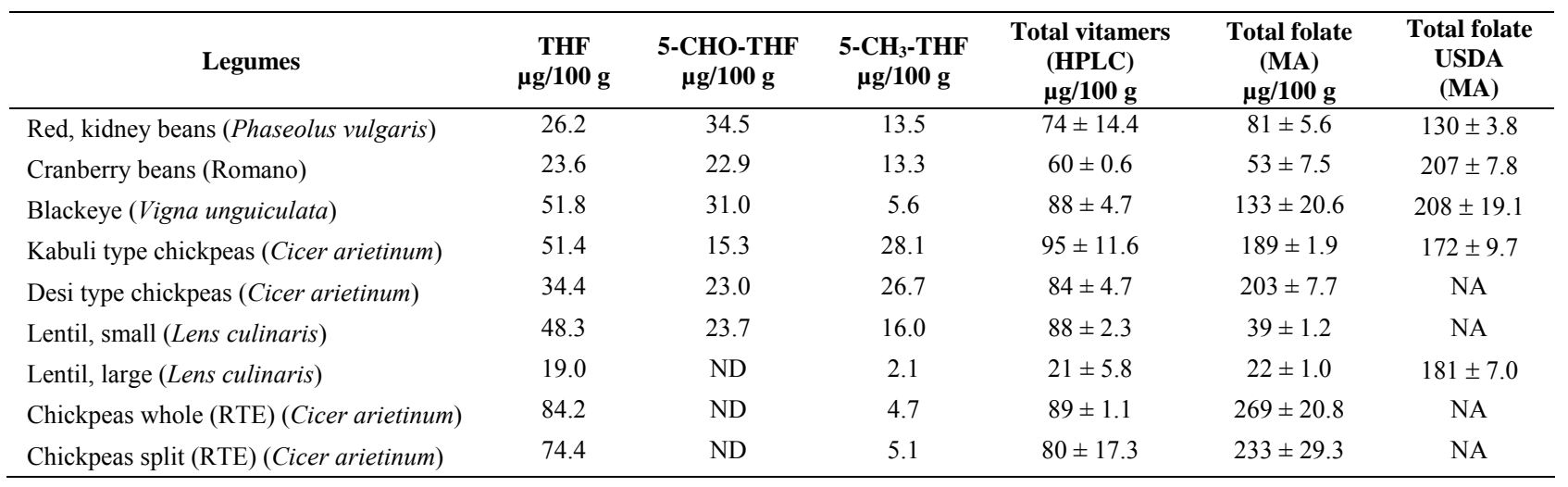

$\mathrm{MA}=$ Microbiological Analysis; ND = Not detectable; NA = Not available. 
lar to folate contents of cooked legumes, soaked overnight for $16 \mathrm{~h}$, reported by Hoppner and Lampi [24]. However, the total folate contents were lower than those reported in the USDA Nutrient Database (Table 3). Measurement of folate contents by different extraction methodologies, as well as the nature of the growing conditions, weather, location and cultivar has an impact on food components [25-28] storage conditions, legumes may become dry and cracked, which may influence the loss of vitamins from outer layers during soaking, as most B vitamins are located in the outer layers.

Seven varieties of cooked legumes analyzed by HPLC contained $49.9 \%$ of folates in the form of THF; $29.5 \%$ in the form of 5-CHO-THF; and $20.6 \%$ in the form of 5 $\mathrm{CH}_{3}$-THF (Table 3). RTE chickpeas contained mainly 95\% of folates in the THF form (Table 3). The distributions of folates derivatives in kabuli type of chickpeas (Table 3) were higher $\left(28.1 \mu \mathrm{g} / 100 \mathrm{~g}\right.$ for $5-\mathrm{CH}_{3}$-THF, $15.3 \mu \mathrm{g} / 100 \mathrm{~g}$ for 5 -CHO-THF, $51.4 \mu \mathrm{g} / 100 \mathrm{~g}$ for THF) than the results of Ruggeri et al. [27]; $9.1 \mu \mathrm{g} / 100 \mathrm{~g}$ for 5$\mathrm{CH}_{3}$-THF, $6.1 \mu \mathrm{g} / 100 \mathrm{~g}$ for 5-CHO-THF and not detectable for THF. Another researcher, Rychlik et al. [29] determined the folate content of legumes using a stable isotope dilution assays and found that $5-\mathrm{CH}_{3}-\mathrm{THF}$ was the predominate form in frozen peas, dried lentils, dried blackeye peas and mung beans; THF was the most abundant in fresh beans and soybeans; and 5-CHO-THF was predominately found in peanuts.

Typically THF, the most unstable form, was detected in meat and meat products [27,30-32]. The $5-\mathrm{CH}_{3}-\mathrm{THF}$ form was found to be the main folate in vegetables and legumes [22,25,29,30,32-34]. In vegetables, fruit, bread, milk products, potatoes, and meat products, $62 \%$ of all folate forms (THF, 5- $\mathrm{CH}_{3}$ - THF, 5-CHO-THF, 105-HCOfolic acid and $10-\mathrm{HCO}-\mathrm{H}_{2}$ folate) were $5-\mathrm{CH}_{3}$-THF [30]. Our results for cooked varieties of Tajik legumes differed from these published data. These differences may be due to growing conditions, varietal and/or the methodological differences.

The mean differences of folate as measured by the HPLC analysis were approximately $29 \%$ lower than the total folate amounts analyzed by microbiological analysis. Differences may be due to the identification of only three folate forms (THF, 5- $\mathrm{CH}_{3}-\mathrm{THF}$, and 5-CHO-THF) by HPLC analysis that are found in food; therefore, not including other folate compounds which may be found in minute quantities and not measured. The higher total folate values that we found as measured by the microbiological analysis may be due to non-folate compounds that stimulate bacterial growth [30].

In our study, we did not analyze folate in raw legumes. Folate losses may occur through leaching (soaking for 16 h) and cooking. Leaching of folates also depends on the type and variety of legumes [35], size and the surface area to volume ratio during soaking [24]. In our study, for example, small lentils were higher in total folate values $(39 \mu \mathrm{g} / 100 \mathrm{~g})$ compared to large lentils $(22 \mu \mathrm{g} / 100 \mathrm{~g})$; and desi type chickpeas (small) had higher total folate content $(203 \mu \mathrm{g} / 100 \mathrm{~g})$ compared to kabuli type chickpeas (large) which contained $189 \mu \mathrm{g}$ folate/ $100 \mathrm{~g}$.

Differences of folate forms from our study compared to other research may be attributed to discarding the soaking and cooking water rather than the destruction of folate forms during cooking [24,36]. However, legumes soaked overnight for $16 \mathrm{~h}$ have been shown to have higher folate retentions compared to no presoak or quick soak treatments [24]. Folate content of the cooking water was not determined in our study. It has been suggested to use the cooking water from legumes for further consumption [36]. In Tajikistan, the most common way of preparing legumes is cooking the legume and using the water as broth for stew, soup or other food items.

\section{Conclusions}

Iron and folate contents of Tajik varieties of cooked legumes could be used in dietary research and to make recommendations to Tajiks (especially women of childbearing age) to improve their iron and folate status. Using our data and calculations, the dietary iron intake for Tajik women (18 or above) consuming $100 \mathrm{mg}$ of cooked legumes would have an iron intake of $18 \%$ from cranberry and red kidney beans, $17 \%$ peas, $28 \%$ lentils, and $25 \%$ from RTE chickpeas, based on $18 \mathrm{mg}$ of iron per day as advised by Dietary Reference Intakes. The dietary folate intake for Tajik women (18 or above) consuming $100 \mathrm{~g}$ of cooked legumes would have a folate intake of $17 \%$ from cranberry and red kidney beans, $44 \%$ peas, $8 \%$ lentils, and 63\% from RTE chickpeas, based on $400 \mu \mathrm{g}$ of folate.

\section{Acknowledgements}

This project is a contribution of the University of Nebraska Agricultural Research Division, supported in part by funds provided through Hatch Act, USDA and USDA/FAS project number 58-3148-1038.

\section{REFERENCES}

[1] R. Borwankar, T. Sanghvi and R. Houston, "What is the Extent of Vitamin and Mineral Deficiencies?" Food and Nutrition Bulletin, Vol. 28, Supplement 1, 2007, pp. S174-S181.

[2] V. L. Montoya, D. Wink and M. L. Sole, "Adult Anemia: Determine Clinical Significance," Nurse Practitioner, Vol. 27, No. 3, 2002, pp. 38-53. doi:10.1097/00006205-200203000-00007

[3] U. Ramakrishnan, "Nutritional Anemias," CRC Press, 
Boca Raton, 2001.

[4] United Nations Children's Fund and the Micronutrient Initiative, "Vitamin and Mineral Deficiency: A Global Progress Report," 2004.

http://www.ceecis.org/iodine/05_advocacy/04_dar/DAR $\% 20$ VMD\%20Report\%202004.pdf

[5] F. Branca, M. Ferrari, L. Mistura, L. Rossi and S. Tazhibayev, "Micronutrient Status Survey - Tajikistan 2003," 2004.

http://www.idpas.org/SCNReportSite/supplements/Tajiki stan\%20-\%20Micronutrient $\% 20$ Status\%20Survey.pdf

[6] C. Nishida, R. Uauy, S. Kumanyika and P. Shetty, "The Joint WHO/FAO Expert Consultation on Diet, Nutrition and the Prevention of Chronic Diseases: Process, Product and Policy Implications," Public Health Nutrition, Vol. 7, No. 1A, 2004, pp. 245-250. doi:10.1079/PHN2003592

[7] Food and Agriculture Organization, "Preventing Micronutrient Malnutrition a Guide to Food-Based Approaches - Why Policy Makers Should Give Priority to Food-Based Strategies," 1997. http://193.43.36.103/docrep/x0245e/x0245e00.htm

[8] W. J. Broughton, G. Hernandez, M. Blair, S. Beebe, P. Gepts and J. Vanderleyden, "Beans (Phaseolus spp.) Model Food Legumes," Plant and Soil, Vol. 252, No. 1, 2003, pp. 55-128. doi:10.1023/A:1024146710611

[9] M. J. Messina, "Legumes and Soybeans: Overview of Their Nutritional Profiles and Health Effects," American Journal of Clinical Nutrition, Vol. 70, No. 3, 1999, pp. 439S-450S.

[10] P. H. Graham and C. P. Vance, "Legumes: Importance and Constraints to Greater Use," Plant Physyiology, Vol. 131, No. 3, 2003, pp. 872-877. doi:10.1104/pp.017004

[11] S. Yarbaeva, D. Giraud and J. Albrecht, "Legume Intake of Childbearing Aged Women in Rural Tajikistan," Ecology of Food and Nutrition, Vol. 47, No. 2, 2008, pp. 109-125. doi:10.1080/03670240701702370

[12] Food and Agriculture Organization and the World Health Organization, "Vitamin and Mineral Requirements in Human Nutrition: Report of a Joint FAO/WHO Expert Consultation," 2004.

http://whqlibdoc.who.int/publications/2004/9241546123. pdf

[13] A. T. Merchant and M. Dehghan, "Food Composition Database Development for between Country Comparisons," 2006. http://www.nutritionj.com/content/5/1/2

[14] American Association of Cereal Chemists, "Method 40-41B Iron-Spectrophotometric Method," 2000.

http://www.aaccnet.org/ApprovedMethods/summaries/40 $-40-01 . \operatorname{aspx}$

[15] E. W. Murphy, P. E. Criner and B. C. Gray, "Comparisons of Methods for Calculating Retentions of Nutrients in Cooked Foods," Journal of Agricultural and Food Chemistry, Vol. 23, No. 6, 1975, pp. 1153-1157. doi:10.1021/if60202a021

[16] J. I. Rader, C. M. Weaver and G. Angyal, "Use of a Microbiological Assay with Tri-enzyme Extraction for Measurement of Pre-fortification Levels of Folates in En- riched Cereal-Grain Products," Food Chemistry, Vol. 62, No. 4, 1998, pp. 451-465. doi:10.1016/S0308-8146(98)00089-2

[17] Association of Official Agricultural Chemists, "AOAC 45.2.03, AAOC Official Method 944.12 Folic Acid (Pleroylglutamic Acid) Microbiological Methods," Official Methods of Analysis of AOAC International, 17th Edition, Association of Official Agricultural Chemists, Washington DC, 2000, pp. 48-49.

[18] E. S. Osseyi, "Folate Determination in Cereal-Based Foods by High-Performance Liquid Chromatography," Ph.D. Thesis, University of Nebraska-Lincoln, Lincoln, 1998.

[19] U.S. Department of Agriculture, Agricultural Research Service, "USDA Nutrient Database for Standard Reference, Release 20," 2007. http://www.nal.usda.gov/fnic/foodcomp/search/

[20] C. Hotz and R. S. Gibson, "Traditional Food-Processing and Preparation Practices to Enhance the Bioavailability of Micronutrients in the Plant-Base Diets," Journal of Nutrition, Vol. 137, No. 4, 2007, pp. 1097-1110.

[21] S. G. C. Brazaca and F. C. D. Silva, "Enhancers and Inhibitors of Iron Availability in Legumes," Plant Foods for Human Nutrition, Vol. 58, No. 1, 2003, pp. 1-8. doi:10.1023/B:QUAL.0000041140.50758.72

[22] P. M. Finglas, K. Wigertz, L. Vahteristo, C. Witthoft, S. Southon and I. DeFroidmont-Gortz, "Standardisation of HPLC Techniques for the Determination of Naturally-Occurring Folates in Food," Food Chemistry, Vol. 64, No. 2, 1999, pp. 245-255. doi:10.1016/S0308-8146(98)00171-X

[23] T. Tamura, "Determination of Food Folate," Journal of Nutritional Biochemistry, Vol. 9, No. 5, 1998, pp. 285293. doi:10.1016/S0955-2863(98)00013-8

[24] K. Hoppner and B. Lampi, "Folate Retention in Dried Legumes after Different Methods of Meal Preparation," Food Research International, Vol. 26, No. 1, 1993, pp. 45-48. doi:10.1016/0963-9969(93)90104-Q

[25] J. Jastrebova, C. Witthoft, A. Grahn, U. Svensson and M. Jagerstad, "HPLC Determination of Folates in Raw and Processed Beetroots," Food Chemistry, Vol. 80, No. 4, 2003, pp. 579-588. doi:10.1016/S0308-8146(02)00506-X

[26] J.-Y. Han and R. T. Tyler, "Determination of Folate Concentrations in Pulses by a Microbiological Method Employing Trienzyme Extraction," Journal of Agricultural and Food Chemistry, Vol. 51, No. 18, 2003, pp. 5315-5318. doi:10.1021/jf0211027

[27] S. Ruggeri, L. T. Vahteristo, A. Aguzzi, P. Finglas and E. Carnovale, "Determination of Folate Vitamers in Food and in Italian Reference Diet by High-Performance Liquid Chromatography," Journal of Chromatography A, Vol. 855, No. 1, 1999, pp. 237-245. doi:10.1016/S0021-9673(99)00674-3

[28] T. Hyun and T. Tamura, "Trienzyme Extraction in Combination with Microbiologic Assay in Food Folate Analysis: An Updated Review," Experimental Biology and Medicine, Vol. 230, No. 7, 2005, pp. 444-454.

[29] M. Rychlik, K. Englert, S. Kapfer and E. Kirchhoff, "Fo- 
late Contents of Legumes Determined by Optimized Enzyme Treatment and Stable Isotope Dilution Assays," Journal of Food Composition and Analysis, Vol. 20, No. 5, 2007, pp. 411-419. doi:10.1016/j.jfca.2006.10.006

[30] E. J. Konings, H. H. Roomans, E. Dorant, R. A. Goldbohm, W. H. Saris and P. A. Van Den Brandt, "Folate Intake of the Dutch Population According to Newly Established Liquid Chromatography Data for Foods," American Journal of Clinical Nutrition, Vol. 73, No. 4, 2001, pp. 765-776.

[31] L. Vahteristo, P. M. Finglas, C. Witthoft, K. Wigertz, R. Seale and I. de Froidmont-Gortz, "Third EU MAT Intercomparison Study on Food Folate Analysis Using HPLC Procedures," Food Chemistry, Vol. 57, No. 1, 1996, pp. 109-111. doi:10.1016/0308-8146(96)00146-X

[32] L. Vahteristo, K. Lehikoinen, V. Ollilainen and P. Varo, "Application of an HPLC Assay for the Determination of Folate Derivatives in Some Vegetables, Fruits and Berries Consumed in Finland," Food Chemisty, Vol. 59, No. 4, 1997, pp. 589-597. doi:10.1016/S0308-8146(96)00318-4

[33] L. Stralsjo, K. Arkbage, C. Witthoft and M. Jagerstad, "Evaluation of a Radioprotein-Binding Assay (RPBA) for
Folate Analysis in Berries and Milk," Food Chemistry, Vol. 79, No. 4, 2002, pp. 525-534. doi:10.1016/S0308-8146(02)00392-8

[34] D. J. McKillop, K. D. Pentieva, J. M. Scott, J. J. Strain, R. McCreedy, J. Alexander, K. Patterson, J. Hughes and H. McNulty, "Protocol for the Production of Concentrated Extracts of Food Folate for Use in Human Bioavailability Studies," Journal of Agricultural and Food Chemistry, Vol. 51, No. 15, 2003, pp. 4382-4388. doi: $10.1021 / \mathrm{jf0262312}$

[35] J. Dang, J. Arcot and A. Shrestha, "Folate Retention in Selected Processed Legumes," Food Chemistry, Vol. 68, No. 3, 2000, pp. 295-298. doi:10.1016/S0308-8146(99)00202-2

[36] D. J. McKillop, K. Pentieva, D. Daly, J. M. McPartlin, J. Hughes, J. J. Strain, J. M. Scott and H. McNulty, "The Effect of Different Cooking Methods on Folate Retention in Various Foods That Are amongst the Major Contributors to Folate Intake in the UK Diet," British Journal of Nutrition, Vol. 88, No. 6, 2002, pp. 681-688. doi:10.1079/BJN2002733 